\title{
Exploring Secondary School EFL Teachers' Assessment Literacy in Practice: A Case Study in China
}

\author{
Yuanyuan Chen ${ }^{1}$ \\ ${ }^{1}$ School of English Education, Guangdong University of Foreign Studies, China \\ Correspondence: Chen Yuanyuan, School of English Education, Guangdong University of Foreign Studies, No.2 \\ Baiyundadao North, Baiyun District, Guangzhou, China.
}

Received: October 12, 2021

Accepted: November 1, 2021

Online Published: November 3, 2021

doi: $10.5539 /$ elt.v14n12p1

URL: https://doi.org/10.5539/elt.v14n12p1

\begin{abstract}
Assessment literacy (AL) has emerged as an important research field during the past decade, yet it remains a great challenge for secondary school EFL teachers in China to appropriately enact their assessment literacy. Due attention needs to be paid to research upon teachers' conceptions of assessment (CoA) and assessment practice. Based upon a semester's observation of the English classes in a secondary school in China, weekly meetings on English teaching and research, a focus group interview, individual interviews, documents such as the participants' lesson plans and reflective journals, this qualitative study aims at exploring: (1) what are the conceptions of assessment of the participating secondary EFL teachers? (2) what is the teachers' assessment literacy in practice (TALiP)? (3) How could their assessment literacy be enhanced?

Self-reported findings show that the EFL teachers have a wide scope of conceptions of assessment and individual variations in their assessment practices. The former range from knowledge of assessment purposes and criteria to regarding assessment as learning (AaL), and the latter from giving instant feedback of nodding or simple comments to practicing assessment for learning (AfL) in classroom teaching. Findings from observation also reveal that when tempting AaL, the participants could generally achieve AfL to some extent. Implications for further teacher professional development are discussed concerning how to enhance assessment literacy mentoring in internship and in-service training.
\end{abstract}

Keywords: teacher assessment literacy, conceptions of assessment, secondary EFL teacher

\section{Introduction}

Assessment literacy (AL) is an integral part of teacher professional development, and yet is under-explored compared with other perspectives in the current teacher education programs (Tsagari \& Vogt, 2017). According to Fulcher (2012), research into assessment literacy is in its infancy, and there is still a lack of the development of a systematic approach to teachers' assessment literacy (Lam, 2015). However, during the past years, teacher assessment literacy (AL) has become a significant research topic in the field of language assessment and testing in the recent decade (Inbar-Lourie, 2008; Taylor, 2013). Therefore, further research is highly needed to examine the conceptions of teachers' AL and their assessment literacy in practice (TALiP) to investigate the nature and potential measures for enhancing their AL and therefore improving teaching practice in general.

In 2007, Chinese Ministry of Education launched the formative assessment policy and practice accompanied by the long-lasting public examinations which have been the most commonly implemented assessment methods (Chinese Ministry of Education [CMoE], 2007). Before CMoE's launch of assessment policy, there had been few assessment practices other than the summative examinations conducted by the local schools or teachers, particularly in K12 education. In recent years, there has been a trend of formative assessment implemented to better enhance students' performance in the EFL (English as a Foreign Language) classes.

This study, drawing on two contest-winning secondary EFL teachers' interview narratives, classroom observations and journals, based upon the case in GY Secondary School in Guangzhou, China, examines the EFL teachers' conceptions of assessment (CoA) and their assessment literacy in practice (TALiP). So the research aims at answering the question: What are the EFL teachers' conceptions of assessment and how do they implement their TALiP? To be specific, the research answers the following questions:

(1) what are the conceptions of assessment of secondary school EFL teachers? 
(2) What is the teachers' assessment literacy in practice?

(3) How could their assessment literacy be enhanced?

\section{Literature Review}

The concept of assessment literacy (AL) was introduced into the research field of general education before it was then introduced into language education. During the past decades, the notion of AL has changed as researchers have been investigating into the language education field. Generally speaking, there is no fixed definition or notion of AL (Fulcher, 2012; Walters, 2010). Stiggins (1991) was universally considered to be the first to put forward the concept "assessment literacy" of classroom teachers to identify if or when they are capable of differentiating correct and incorrect assessment practices. Then, the most universally adopted working definition of language AL or teacher AL was proposed by Fulcher (2012) when he conducted a study upon the learning needs that the teachers had in language testing and assessment research. Taylor (2013) proposed AL/LAL including four constituencies such as teachers, administrators and professional language testers and test writers. Besides, AL is a major element of The Standards for Teacher Competence in the Educational Assessment of Students (American Federation of Teachers, AFT, National Council on Measurement in Education, \& National Education Association, 1990). Teachers' AL in practice has long been associated with a belief system of assessment. In terms of language education research, there are so far few studies that have examined the the relationship between teachers' individual beliefs or conceptions of assessment and their assessment literacy in practices (TALiP). As Xu and Brown (2016) argue, without the teachers' knowledge base on assessment and the discipline as well as assessment ethics, there would be no standards or criteria by which the extent and appropriateness of assessment practices could be evaluated. Moreover, TALiP is highly situated and is closely intertwined with the teachers' conceptions of assessment and the actual local contexts and the teachers' pedagogical content knowledge.

\section{Research Methodology}

\subsection{Contexts and Participants}

With the implementation of the top-down mandate educational reform, the provincial teaching contest was introduced in the year of 2017, in response to the local educational reform and the national EFL teaching reform. It had been considered the most authoritative and influential teaching contest in K12 education ever since then. The contest has been conducted three times every other year. Through the provincial teaching contest, the excellent teachers would be chosen and be trained to further enhance their teaching in terms of pedagogical theories and practice. The participating teachers were required to orally present their lesson plans for a whole unit based upon the topic Healthy Diet from the mandate English textbook 9A Unit 6, which was given to the contestants just one hour prior to the presentation. After this round of presentation, with the committee's evaluation, the top ten teachers will run for the final, and they will prepare for one hour with the materials provided by the organizing committee and deliver a 20-minute class to around 20 students.

I chose GY Secondary School as the research site due to the following reasons. Firstly, GY Secondary School is a prestigious renowned school in the city, in which English teaching and teacher professional development have been considered the top priority in the school and the students' English proficiency has proved to top among many schools in GZ, and the students stand out in many national and provincial English contests. The school teachers has been actively participating in the provincial English teaching contests, therefore the school has attracted the attention of the provincial education bureau and has got the chance to participate in the teaching contest every other year. Secondly, during the past year, I had built up friendly and trustworthy relations with both the school administration and the EFL teacher team, which is of vital importance in conducting qualitative case studies (Connelly \& Clandinin, 2006; Chen, 2004). Moreover, the teachers in the school have more advantages of learning the frontier theories and practical skills in English teaching and learning due to the fact that they have more access than other schools to foreign language resources. Thus, the teachers are more aware of the challenges and are more willing to take the challenges and face the pressure in their teaching practice.

With the previous participation in the provincial contests, the school has set up a division for teacher development, particularly for novice teacher development and contest training delivered by expert teachers and teacher educators. With constant efforts devoted to teacher professional development, the school has held multiple lectures and workshops by the most famous professors and scholars in EFL teacher education.

In this research, the teacher participants Ms. Anne and Ms. Yannie had been working in the teaching profession for six years and 20 years respectively. The vice principal, Ms. Claire had been in the EFL teaching profession for 
sixteen years and implemented teacher education including assessment literacy training program. In addition, Ms. Yannie was the English teaching team leader (the names of the teachers are pseudonyms).

\subsection{Data Collection and Analysis}

Data collection and analysis were conducted throughout the semester from March to August, 2021. The data collected include interview narratives of the participating teachers, the vice principal of GY Secondary School, class observation notes and pictures together with the teachers' preparation videos for the teaching contest. And certificates of honor and awards as well as school documents were provided for triangulation. I took class observation notes, made interviews with the teachers for 126 minutes in total and with the vice principal for 40 minutes. Small talks for further information and clarification were also conducted when necessary.

The Grounded Theory (Corbin \& Strauss, 2015) was adopted in the data analysis of the research. The interview narratives, contest preparation videos, classroom observation notes and the teachers' teaching plans were transcribed verbatim manually and sent back to the participants for double-check for accuracy. Then the analysis was then conducted with regular references back to the research questions and the teachers' conceptions of assessment literacy and their TALiP were therefore demonstrated clearly through the data.

\section{Findings and Discussions}

The findings of the three research questions are presented as follow.

$R Q$ 1: what are the conceptions of assessment (CoA) of secondary school EFL teachers?

\subsection{Teachers' Conceptions of Assessment}

As Xu and Brown (2016) contend, conceptions of assessment denote the belief systems that teachers have about the nature and purposes of assessment, and that encompass their cognitive and affective responses. The cognitive dimension denotes what teachers believe is true and false about assessment. The affective dimension denotes emotional inclinations that teachers have about various aspects and uses of assessment. As demonstrated in both Anne and Yannie's contest preparation videos and their classroom observation notes, they showed conceptions of assessment in different perspectives. Anne introduced within her presentation that she would give students a 3-minute quiz to test students' awareness of what healthy diet indicates, constant feedback to students for what they did well and what needed further discussion, and she would group the students so that students in the same group would get the same score because she believed that collaborative learning and scoring the same for the whole group would help students achieve better results. She also mentioned that she would give students homework as a means of testing how well they had learned in the class. She had strong awareness of assessment of learning. As she explained in her interview,

I found that without any assessment the students wouldn't really listen to you and follow you, no matter how well you get on terms with them, because only when I give them a task they would take the initiative to do it. Otherwise, they would rather lie down and forget about everything they learned in the class until it's time for the midterm test or the final exam. However, when I began to constantly assess them in various ways, like challenging them with questions which help them review and help with further study, I found it really worked. Only a few students would review and keep learning even without any homework or exams, yet some students will have to rely on some exams, quizzes or external pressure.

Similar to Anne's conceptions of assessment, Yannie also expressed her understanding of the importance of assessment. Yannie argued that what she focused on was students' classroom involvement and performance. She would give different types of students different kinds of assessment, with particular attention to the students who didn't excel in academic performance, which turned out to be encouraging to the students and helped them build up confidence. Her understanding of the role of assessment for students made her fully aware of every particular student's emotions and needs.

I remember there were two boys, Bob and Sean (pseudonym). Bob was excellent in his English, particularly in his American accent; though he didn't do well in other subjects, he was encouraged and became very active in my English class. I used to group him with three other students of different English levels, one with good oral English, the other two good at Chinese and Physics respectively. I would give different students in the same group different tasks, so they would work together to finish the task. Through the collaboration, they would learn from each other and each would also build up confidence by helping others. Of course they would receive the same score in the same group, otherwise it would be meaningless in grouping and it would be unfair for those who got the lower score. Sean graduated several years ago, he didn't do well in any subject, including English. But I paid a lot of attention on this boy. Because I got to know that his parents just got divorced and he was very low for quite a while. He was smart, but not 
attentive in class. He was a good soccer player and wanted to study in the soccer school in QY, which is two hours' drive from here. So from then on, I didn't score him or evaluate his performance with the same criteria with the other students. I asked him to give a presentation on soccer and his goal in the future. Then it was the open day of the school. I invited him to share in the class and though he didn't speak excellent English, his sincerity and passion for soccer touched everyone, including many parents and other teachers. He went to the soccer school one year later as he wished.

It is obviously demonstrated in Yannie' $\mathrm{s}$ case that her target of assessment would vary from individuals to groups according to different teaching contents and objectives. And through the variations in assessment, students will develop both independent learning ability and collaboration skills. She also showed strong affective consideration for the students by encouraging them with different assessment methods. As both Yannie and Anne have demonstrated in their cases, both of them had strong awareness of the role that assessment plays in teaching and learning, and both of them showed their affective concerns for the compromises they could make for every individual student. Those cognitive and affective concerns were not only manifested in their preparatory contest videos but also in their daily classroom teaching. Those conceptions of assessment were based upon their knowledge of assessment purposes, content, and methods, knowledge of assessment interpretation and knowledge of student involvement in assessment, which are as a whole regarded as the teachers' knowledge base (Xu \& Brown, 2016).

\section{$R Q$ 2: What are the teachers' assessment literacy in practice?}

\subsection{EFL Teachers' Assessment Literacy in Practice (TALiP)}

From the interview data, three perspectives in the EFL teachers' TALiP have been shown, namely their instant individual feedback to students' classroom performance, students' peer assessment, teachers' task-based instructions.

\subsubsection{Anne's TALiP}

As is demonstrated in Anne's conceptions of assessment, she practiced her beliefs in assessment by grouping students so they could do group work and peer assessment afterwards. Peer assessment has been highlighted in formative assessment in EFL teaching, as it provides space for students to perform assessment as learning during the assessment process, in which the peers could reflect on their respective performances, exchange their understanding, and making negotiations. This process would facilitate the assessment as learning (AaL) purpose in the assessment perspective.

I would give my students a lot of chances to evaluate their peers' performance, particularly in the weekly reading club class. Every time before the reading club class on Wednesday afternoon, the students will get ready to share what they have read and reviewed before the class within their groups first. In this stage, the students will comment on each other's sharing within the group. And then one student will be recommended by each group to share with the whole class what they prepared. Afterwards, the whole class together with me will give our feedback and comments. So through the whole class, we have mutually understood not only what the students shared in the books but only extended our understanding of each other in terms of our values of the world.

For maximum efficiency of assessment, Anne also practiced multi-level assessment by pairing students with different proficiency levels. Through the pairing, students of heterogeneous English proficiency could work together so synergy could be achieved.

\subsubsection{Yannie's TALiP}

As Yannie demonstrated in her oral presentation videos and her classroom teaching, she implemented multiple ways of assessment which echoed with her wide range of conceptions of assessment. She had ample knowledge of assessment purposes and knowledge of the benefits of involving students in assessment (e.g., self- and peer assessment and transparent learning objectives or standards) (JCSEE, 2015). Her assessment practice best manifested her knowledge and beliefs in assessment in terms of her disciplinary knowledge and pedagogical content knowledge as well as her knowledge of assessment purposes, content and methods.

I know that simply testing the students with monthly exams and midterm and final exams would be too boring and cruel for some of the students, and they will lose interest in learning. And the purpose of testing is not to set up barriers and fear for the students, instead, they should be the impetus and even a way of learning for students. They will find that classroom activities, peer assessment, group tasks, and exams are set to help them better understand and grasp what they are supposed to learn and they are important and necessary skills or knowledge for them. I would usually assign different students different homework according to their interests, particularly 
for those who don't do well in their study, so in this way they would develop interest and confidence in English learning. As I shared just now, Sean is the kind of students who could only improve his learning through activities instead of exams. And English is a subject that requires a lot of practice. For some students, monotonous drills would be attractive enough while for many various ways of assessment would be more fun for them to be interested.

From the interview narratives, videos and the classroom observation of both Anne and Yannie, it's clearly demonstrated that both teachers have a wide scope of knowledge of assessment and have extensive assessment practices based upon their knowledge of the English discipline and pedagogical contents, assessment purposes, methods and students' involvement in assessment. What they didn't share was the relations between the direct results of students' performance and their formative assessment during the daily classroom teaching and learning. However, it can be shown from their classes final exam results that their students did achieve better academic results than the other classes.

\section{$R Q$ 3: How could their assessment literacy be enhanced?}

\subsection{Enhancement of EFL Teachers' CoA and TALiP}

The EFL teachers have to a large extent demonstrated abundant conceptions of assessment and extensive assessment practices, while at the same time they didn't explore the immediate relations between their assessment practices and the students' academic performances, though both of them were teaching contest award winners. Besides, they didn't show obviously the awareness of the assessor's role in conducting assessment practices and when arguing on their conceptions of assessment. Enhancing EFL teachers' conceptions and practices of assessment in language teaching and learning proves to be vital in teacher professional development.

\subsubsection{EFL Teacher Assessment Literacy Development}

It's shown through the interviews that there is a lack of assessment literacy training in secondary schools, even in the top schools. Compared with the abundant formative assessment training programs in the tertiary education, particularly in some top foreign studies university, there is an urgent need of more training programs for teacher assessment literacy in K12 education. Through the top-down training programs, EFL teachers will immediately develop their knowledge andunderstanding of teacher assessment literacy (AL), which serves as the knowledge base that supportsteachers' cognitive and affective understanding and consideration in assessment practices (Pastore \& Andrade, 2019). As Ms. Claire argued,

The teachers didn't realize the role exams and assessment play in enhancing students English learning until we observed the classes. Few teachers had any idea about assessing students in appropriate ways and had little idea about what assessment was. The only assessment they resorted to after teaching was the endless paper exams, which made both the teacher and student exhausted. Then after the classroom observation, we diagnosed that there was an urgent need of teacher professional training. And we invited the key professor in EFL teaching and assessment in China from the university to give us a lecture on assessment. Professor Lorry's lecture opened our eyes, as he introduced the key ideas about assessment and what teachers could do in classroom teaching to assessment students' performance, so that the teacher could practice assessment of learning (AoL), assessment for learning (AfL) and assessment as learning (AaL).

It's demonstrated that with the training program teachers' awareness and conceptions of assessment will be greatly enhanced and their assessment literacy in practice will also be improved (Afshar \& Ranjbar, 2021). Both Anne and Yannie's success in the contests showed their trajectories of teaching practice throughout the training program, and their conceptual changes in assessment are also echoed in their practice.

\subsubsection{Assessment of Teachers' Assessment Literacy in Practice}

It's also important to assess the teachers' assessment literacy in practice so that their practice could be effectively implemented. The local government and the school administration can take the assessor's role in this part, and systematic criteria could be set up to assess the school's and teachers' assessment literacy and the practice.

\section{Conclusion}

we have examined the EFL teachers' conceptions of assessment and their assessment literacy in practice in a secondary school in China based upon their oral presentations of teaching plans for the provincial teaching contests and longitudinal classroom observations together with interviews. It's found that the EFL teachers have a wide scope of conceptions of assessment (CoA) and individual variations in their assessment practices (TALiP). Their conceptions of assessment range from knowledge of assessment purposes, methods and criteria to regarding assessment as learning $(\mathrm{AaL})$ and taking assessment ethics into consideration, and their assessment practices range 
from giving instant feedback to practicing assessment for learning (AfL) in classroom teaching and learning. Findings from the interviews and classroom observations also reveal that when tempting AaL, the participants could to a large extent achieve AfL out of the gap between knowledge and practice. Implications for further detailed teacher professional development programs are discussed concerning how to enhance teachers' assessment literacy mentoring in both internship and in-service training so as to enhance teachers' assessment literacy and professional development.

\section{Acknowledgments}

This research was financially supported by the project “Exploring Secondary EFL Teachers' Professional agency in the Stream of Education Reform" granted by Guangdong University of Foreign Studies. The support is gratefully acknowledged.

\section{References}

Afshar, H., \& Ranjbar, N. (2021). EAP teachers' assessment literacy: From theory to practice. Studies in Educational Evaluation, 70, 1-14. https://doi.org/10.1016/j.stueduc.2021.101042

Corbin, J., \& Strauss, A. (2015). Basics of qualitative research: Techniques and procedures for Developing Grounded Theory (4th ed.). Thousand Oaks: Sage.

Fulcher, G. (2012). Assessment literacy for the language classroom. Language Assessment Quarterly, 9(2), 113-132. https://doi.org/10.1080/15434303.2011.642041

Inbar-Lourie, O. (2008). Constructing a language assessment knowledge base: A focus on language assessment courses. Language Testing, 25(3), 385-402. https://doi.org/10.1177/0265532208090158

Joint Committee on Standards for Educational Evaluation. About JCSEE[EB/OL]. [2015-4-29]. Retrieved from https://www.jcsee.org/

Lam, R. (2019). Teacher assessment literacy: Surveying knowledge, conceptions and practices of classroom-based writing assessment in Hong Kong. System, 81, 78-89. https://doi.org/10.1016/j.system.2019.01.006

Pastore, S., \& Andrade, H. L. (2019). Teacher assessment literacy: A three-dimensional model. Teaching and Teacher Education, 84, 128-138. https://doi.org/10.1016/j.tate.2019.05.003

Taylor, L. (2013). Communicating the theory, practice and principles of language testing to test stakeholders: Some reflections. Language Testing, 30(3), 403-412. https://doi.org/10.1177/0265532213480338

Tsagari, D., \& Vogt, K. (2017). Assessment literacy of foreign language teachers around Europe: Research, challenges and future prospects. Papers in Language Testing and Assessment, 6(1), 41-63.

Walters, F. S. (2010). Cultivating assessment literacy: Standards evaluation through language- test specification $\begin{array}{llll}\text { reverse engineering. Language Assessment } & \text { Quarterly, 7(4), 317-342. }\end{array}$ https://doi.org/10.1080/15434303.2010.516042

Xu, Y., \& Brown, G. T. L. (2016). Teacher assessment literacy in practice: A reconceptualization. Teaching and Teacher Education, 58, 149-162. https://doi.org/10.1016/j.tate.2016.05.010 


\section{Appendix}

\section{Interview protocol for participants}

1) When you design your class, what different parts do you include in your teaching plan? Why?

2) When you design activities, what kinds of activities do you design? What are your criteria in choosing or designing activities? why?

3) Do you assess your students in your teaching? What kinds of assessment do you consider?

4) How do you assess your students' performance? Giving scores, comments, signals, or designing some assessment activities? If so, how?

5) Do you assign any homework for your students? If so, what kind of homework do you give them? For what purpose?

6) What do you think should be done to enhance teachers' assessment literacy?

7) If you were the school principal, what would you do?

\section{Copyrights}

Copyright for this article is retained by the author(s), with first publication rights granted to the journal.

This is an open-access article distributed under the terms and conditions of the Creative Commons Attribution license (http://creativecommons.org/licenses/by/4.0/). 